\title{
Photocatalytic Activity of Graphene/ZnO Nanocomposite Fabricated by Two-step Electrochemical Route
}

\author{
A R NANAKKAL and L K ALEXANDER* \\ Department of Physics, University of Calicut, Kerala 673 635, India \\ Email: LKA@uoc.ac.in
}

MS received 1 September 2016; revised 1 November 2016; accepted 3 November 2016

\begin{abstract}
Graphene-Zinc oxide nanocomposite was synthesised by a novel, facile and environment-friendly two-step electrochemical route aimed at water purification by photocatalysis. The X-ray diffraction, Raman spectroscopy and electron microscopy demonstrate successful implementation of electrolytic route for the synthesis of graphene-metal oxide nanocomposite. UV-Visible diffuse reflectance spectroscopy and photoluminescence measurements were also used to characterise the samples. Based on this work, it is found that for the UV incident radiation, Graphene- $\mathrm{ZnO}$ nanocomposite shows an enhanced photocatalytic activity over $\mathrm{ZnO}$. The photocatalytic activity of annealed graphene $-\mathrm{ZnO}$ was compared to a standard catalyst Degussa $\mathrm{P} 25 \mathrm{TiO}_{2}$. The electrochemical synthesis technique is envisioned to open a reliable, cost-effective and environment sensitive method to fabricate graphene-metal oxide nanocomposites which could lead to various applications especially for photocatalysis.
\end{abstract}

Keywords. Graphene-metal oxide; nanocomposites; electrochemistry; photocatalysis; water purification.

\section{Introduction}

Graphene (GN), an allotrope of carbon material, conquered the world of nanotechnology in the last decade because of its unique properties. ${ }^{1}$ The properties of graphene, such as 2D structure, large surface area $\left(\sim 2600 \mathrm{~m}^{2} / \mathrm{g}\right)$, theoretical high mobility of charge carriers $\left(\sim 200000 \mathrm{~cm}^{2} / \mathrm{Vs}\right)$, etc., made graphene more attractive for use as a phase matrix for developing nanocomposites using nanoparticles aiming at potential photocatalytic applications. ${ }^{2-8}$ Among the photocatalysts, $\mathrm{TiO}_{2}$ and $\mathrm{ZnO}$ are two remarkable nanoparticles because of their non-toxicity, stability and low cost. ${ }^{9-12}$ It is reported that $\mathrm{ZnO}$ shows better efficiency than $\mathrm{TiO}_{2}$ for the degradation of some organic dyes during photocatalytic process. ${ }^{10}$ Moreover, it is reported that the electron mobility of $\mathrm{ZnO}$ is higher than of $\mathrm{TiO}_{2}{ }^{11,13}$ The widely studied compound, $\mathrm{ZnO}$ is a semiconductor metal oxide material with a wide band gap energy of $3.37 \mathrm{eV} .^{12,14}$ The quick recombination of photogenerated electron hole pairs is considered as a major problem for employing $\mathrm{ZnO}$ as a catalyst in photocatalytic applications. ${ }^{10,11}$ One of the ways adopted to address this issue is by hybridisation of $\mathrm{ZnO}$ with graphene to form graphene- $\mathrm{ZnO}$ nanocomposite. ${ }^{10,11,15}$

Since the properties of graphene and its composites depend on the synthesis route, researchers employed

\footnotetext{
*For correspondence
}

different methods - both for the synthesis of graphene and for the fabrication of graphene nanocomposites. ${ }^{16}$ Graphene can be synthesised using various techniques such as chemical vapour deposition (CVD), ${ }^{17}$ exfoliation of graphite, ${ }^{18}$ electrochemical method, ${ }^{19}$ etc. Among the techniques, electrochemical method was reported as a reliable and low cost method to produce highly pure graphene. ${ }^{19-21}$ For the fabrication of graphene based nanocomposites, different methods like reduction method, hydrothermal method, electrochemical method, various ex situ methods, etc., are reported. ${ }^{16,22-25}$ Among them the electrochemical deposition method is regarded as a facile, speedy, cost effective and green technique. Moreover, it is a reliable method for controlling the material properties such as size, shape and percentage of functionalisation by changing the variables like molarities of electrolytes, $\mathrm{pH}$ of the electrolytic solution, power supply voltage and time of electrolysis. ${ }^{16}$ Majority of the composites reported to be synthesised by electrochemical method was focussed on graphene-noble metal composites such as GN-Pt, ${ }^{26} \mathrm{GN}-\mathrm{Au},{ }^{16}$ etc. We could not find any report on successful anchoring of metal oxide nanoparticles like $\mathrm{ZnO}$ on graphene sheets by the electrochemical method.

In this paper, we report the successful synthesis of graphene- $\mathrm{ZnO}$ nanocomposite by the electrolysis method. A three-step process was followed for the synthesis. X-ray diffraction (XRD) and Raman spectroscopy were utilised for structural characterisation of samples. 
The morphology of the samples was analysed using field emission scanning electron microscopy (FE-SEM) and high resolution transmission electron microscopy (HR-TEM). UV-Visible diffuse reflectance spectroscopy (UV-Vis DRS) was used to obtain the band gap energy. Photoluminescence (PL) measurements on the composites were made to obtain preliminary information on the photocatalytic capability of the nanocomposites. The photocatalytic activity studies were conducted in a photoreactor using UV light source. In order to analyse the rate of degradation of methylene blue (the dye impurity) solution with respect to the irradiation time, UV-Visible spectroscopy was used. We have compared and analysed photocatalytic reaction rates of $\mathrm{ZnO}$ and $\mathrm{GN}-\mathrm{ZnO}$ nanocomposite.

\section{Experimental}

\subsection{Synthesis of Graphene and Graphene nanocomposite by electrochemical process}

The design of electrolytic cell set up consist of graphite rods (purity 99\%, metals basis, Alfa Aeser), sodium chloride, zinc sulphate (Merck), and conc. sulphuric acid (purity 98\% ACS Empesti, Merck). The synthesis process can be categorised into three steps (schematic representation is shown in the Figure 1): (i) Synthesis of graphene by electrolysis, (ii) Modification of as-synthesised graphene sheets by introducing defects, and (iii) Functionalisation of modified graphene sheets using $\mathrm{ZnO}$ nanoparticles by electrolysis. In the first step, an appropriate constant DC voltage was applied across two fresh graphite rod electrodes (duration $60 \mathrm{~min}$ ) dipped in $0.01 \mathrm{M}$ of sodium chloride electrolytic solution to obtain graphene sheets on anode graphite rod. The detailed description of the mechanism involved in this process was reported by Low et al. ${ }^{27}$ Then, the graphene coated electrode was treated with sulphuric acid $(0.002 \mathrm{M})$ so as to introduce more defects on graphene sheets. In the third step (functionalisation), the graphene-deposited graphite rod was employed as cathode and zinc sulphate solution $(0.01 \mathrm{M})$ was used as electrolyte. Then, the electrolysis led to deposition of $\mathrm{ZnO}$ nanoparticles on the graphene sheets resulting in $\mathrm{GN}-\mathrm{ZnO}$ composite. The functionalisation time (Step 3) was $50 \mathrm{~min}$. The resultant powder collected from the cathode was oxidised by drying in an oven. The freshly synthesised $\mathrm{GN}-\mathrm{ZnO}$ sample (via electrolysis) was annealed at $500^{\circ} \mathrm{C}$ for $2 \mathrm{~h}$ in a furnace. The resultant powder was labelled as $\mathrm{GN}-\mathrm{ZnO}(\mathrm{h})$. To obtain $\mathrm{ZnO}$, appropriate potential was applied for one hour across two fresh graphite rod electrodes dipped in $0.01 \mathrm{M}$ zinc sulphate electrolyte solution. The collected powder (from the cathode) was taken to a oven and dried at $60^{\circ} \mathrm{C}$. The as-synthesised $\mathrm{ZnO}$ was heated in a furnace at $500^{\circ} \mathrm{C}$ for $2 \mathrm{~h}$ to get $\mathrm{ZnO}(\mathrm{h})$ sample. In all the electrolysis process a DC voltage of $14 \pm 1 \mathrm{~V}$ was applied.

\subsection{Material characterisation}

The crystallographic characterisation of the samples was carried out using X-ray diffraction (XRD) technique (Rigaku $600)$ at $\mathrm{Cu} \mathrm{K} \alpha(\lambda=1.542 \AA)$. The Raman spectra of graphene samples were obtained using micro Raman spectrometer (Fischer Scientific DXR Raman $532 \mathrm{~nm}$ ). The morphology of the samples was studied using SEM (Hitachi SU 6600-FESEM) and HRTEM (JEOL - JEM 2100, $200 \mathrm{kV}$ ). The reported UV-Vis spectra (including DRS) were done using UV-Vis spectrophotometer (JASCO V-55). Photoluminescence (PL) study was carried out using fluorescence spectrometer (Perkin Elmer LS 55).

\subsection{Photocatalytic experiments}

Photocatalytic studies on the samples were conducted by measuring the degradation of methylene blue solution (MB): $0.1 \mathrm{~g}$ of catalyst was added to $50 \mathrm{~mL} \mathrm{MB}$ solution (10 ppm)

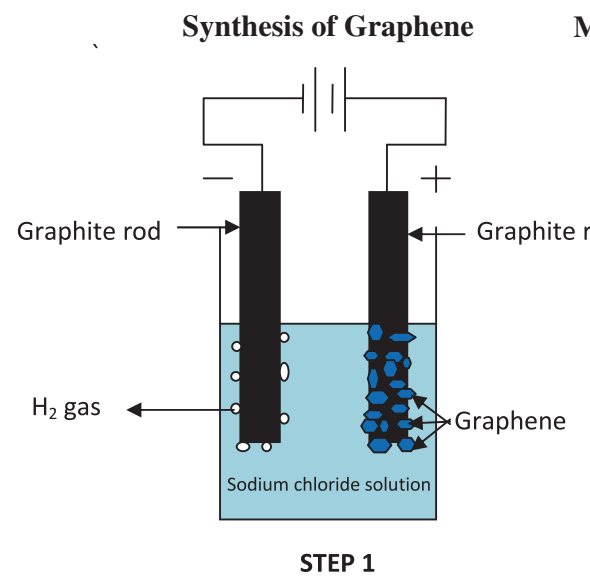

Modification of Graphene

Functionalisation of Graphene

Figure 1. Schematic illustration of three-step synthesis. 
taken in a beaker and the resultant mixture was stirred continuously for $30 \mathrm{~min}$ in dark room condition. In order to attain adsorption - desorption equilibrium between dye solution and the catalyst, the mixture was kept in a dark room for additional $1.5 \mathrm{~h}$. The mixture in equilibrium was then exposed to UV light. The solution samples were collected at fixed time intervals during UV irradiation. UV-Visible spectra of the irradiated samples were taken. Photocatalytic experiments on $\mathrm{ZnO}(\mathrm{h}), \mathrm{GN}-\mathrm{ZnO}$ and $\mathrm{GN}-\mathrm{ZnO}(\mathrm{h})$ were done under UV light using Luzchem LZC-4X photo reactor.

\section{Results and Discussion}

\subsection{Characterisation of graphene and $\mathrm{GN}-\mathrm{ZnO}$}

The XRD of the graphene shows three peaks: a main peak at an angle $2 \theta=26.2^{\circ}$ corresponding to the (002) reflection of graphene (Figure 2(a)) and the minor characteristic peaks of graphitic compound at $2 \theta=44.3^{\circ}$ and $2 \theta=54.4^{\circ}$ corresponding to (101) and (004), respectively. The XRD spectrum matches well with JCPDS file no. 75-1621. The presence of phase-pure $\mathrm{ZnO}$ in the graphene-based composite was confirmed by X-ray diffraction pattern of the samples. As shown in Figure 2(b), all the peaks of the graphene- $\mathrm{ZnO}$ nanocomposite could be indexed and was found in agreement with JCPDS file no.75-1621 combined with file No. 36-1451. ${ }^{22,28,29}$ Figure 3(a) shows XRD pattern for $\mathrm{ZnO}$ nanoparticles prepared by electrochemical route. The XRD pattern of GN-ZnO is shown in Figure $3(\mathrm{c})$. It was reported that annealing to a higher temperature can increase the crystallinity of $\mathrm{ZnO}$. Therefore, $\mathrm{ZnO}$ and $\mathrm{GN}-\mathrm{ZnO}$ were heated to $500^{\circ} \mathrm{C}$. The resultant XRD is shown in Figure 3 (b and d). As seen, the intensity of $\mathrm{ZnO}$ peak dominates over the peaks of

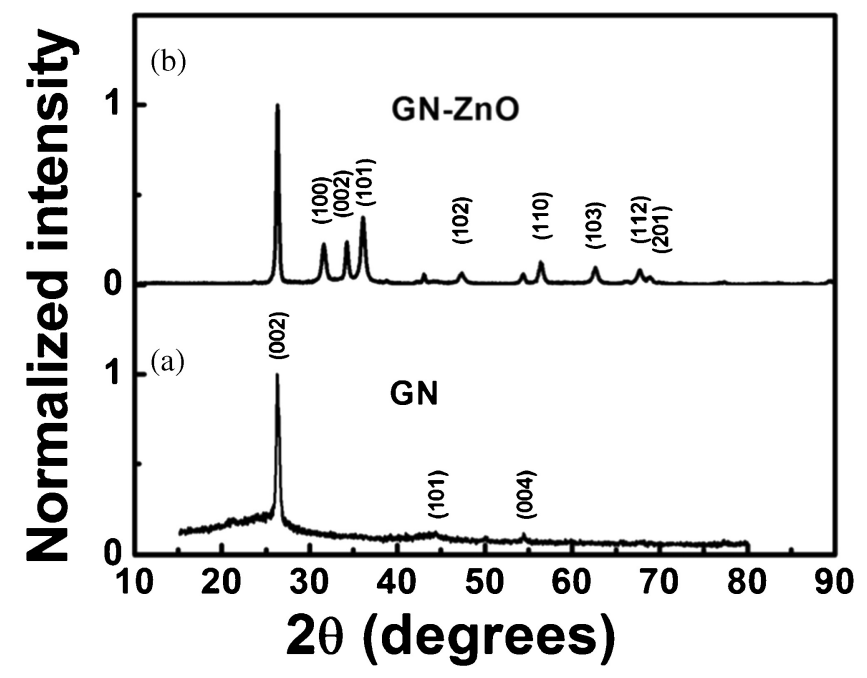

Figure 2. XRD patterns of (a) graphene and (b) GN-ZnO. Peaks of graphene are left un-indexed in Figure (b). graphene in the spectrum (Figure 3(d)). This is expected for the reason that $\mathrm{ZnO}$ got better crystallinity on heating. This is attributed to the change in crystal size. ${ }^{30}$ Particle size of the samples were estimated from the well-known Debye-Scherrer's formula: $d=K \lambda$ / $\beta \cos \theta$; where, $d$ is the crystal size, $\lambda$ is the wavelength of irradiation used, $K$ is the Scherrer constant (0.9), $\beta$ is the full width at half maximum and $\theta$ is the Bragg angle. The particle size in all the samples was found to be in the range $20-30 \mathrm{~nm}$.

Raman Spectroscopy was used for further confirmation of graphene formation by electrolytic method. In general, Raman spectroscopy is a powerful technique for the characterisation of all types of carbon nanostructures, especially graphene. ${ }^{31}$ The presence of $\mathrm{G}$ and

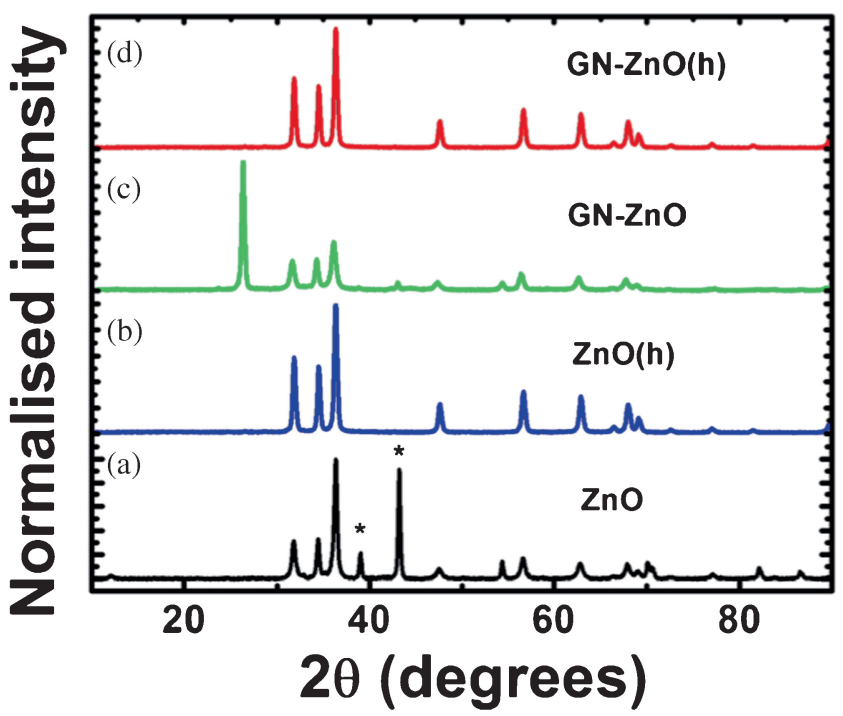

Figure 3. $\mathrm{XRD}$ patterns of (a) $\mathrm{ZnO}$, (b) $\mathrm{ZnO}$ heated at $500^{\circ} \mathrm{C}$, (c) $\mathrm{GN}-\mathrm{ZnO}$, and (d) $\mathrm{GN}-\mathrm{ZnO}$ heated at $500^{\circ} \mathrm{C}$. Starred peaks indicate the peaks of zinc.

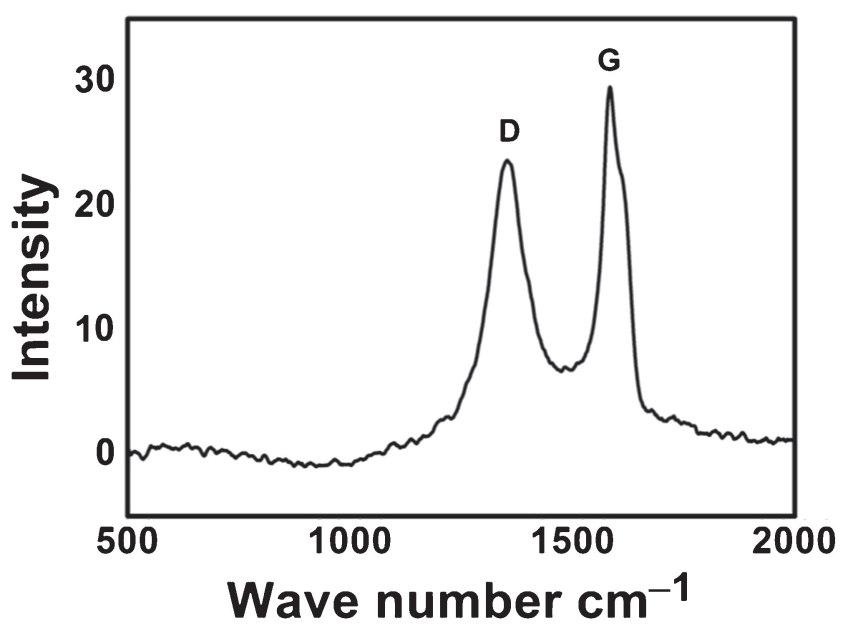

Figure 4. Raman spectrum of graphene obtained in first step of the electrolytic process. 

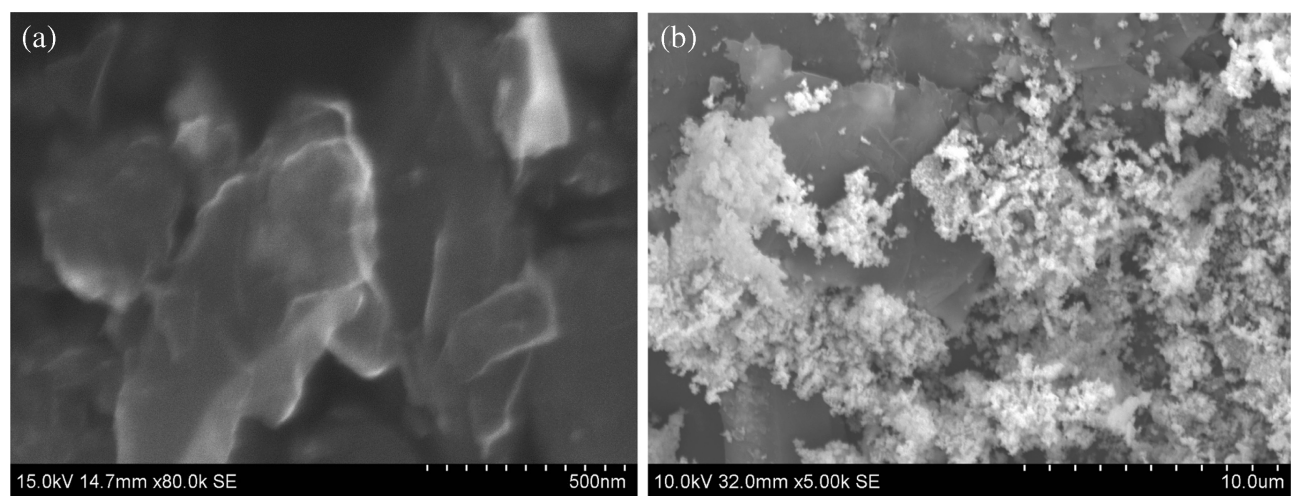

Figure 5. FE-SEM images of (a) graphene and (b) GN-ZnO nanocomposites.

D bands in the Raman spectrum describes the features of nanostructures. ${ }^{31}$ Here, Raman spectrum shows characteristic peaks at $1350 \mathrm{~cm}^{-1}$ and $1581.8 \mathrm{~cm}^{-1}$ for $\mathrm{D}$ band and $\mathrm{G}$ band, respectively (Figure 4). The $\mathrm{G}$ band arises due to first order scattering of the $\mathrm{E}_{2 \mathrm{~g}}$ mode indicating the in-plane stretching motion of $\mathrm{sp}^{2} \mathrm{C}-\mathrm{C}$ bond. The $\mathrm{D}$ band, considered as the disorder peak, originate from $\mathrm{sp}^{3}$ defect-based breathing mode phonons of $\mathrm{A}_{1 \mathrm{~g}}$ symmetry. ${ }^{23,24,32}$ The $\mathrm{D}$ band to $\mathrm{G}$ band intensity ratio $\left(\mathrm{I}_{\mathrm{D}} / \mathrm{I}_{\mathrm{G}}\right)$ is commonly treated as a measure of defects or disorder. ${ }^{11}$ The $\mathrm{I}_{\mathrm{D}} / \mathrm{I}_{\mathrm{G}}$ ratio was found to be 0.88 , which underlines the formation of graphene sheets. ${ }^{23,33-35}$ Based on XRD and Raman spectroscopy, it is clear that the graphitic nanomaterial formed in the first step of electrolysis process was few-layer graphene sheets.

Morphology of the samples was investigated using SEM analysis. Figure 5 ( $a$ and $b$ ) shows the FE-SEM images of $\mathrm{GN}$ and GN-ZnO, respectively. The HRTEM images are shown in Figure 6. From the SEM and HR-TEM images, it is clear that $\mathrm{ZnO}$ nanoparticles are intensely decorated on graphene sheets.

The UV-Visible absorbance spectra of the samples $\mathrm{ZnO}, \mathrm{ZnO}(\mathrm{h}), \mathrm{GN}-\mathrm{ZnO}$ and $\mathrm{GN}-\mathrm{ZnO}(\mathrm{h})$ are shown in Figure 7. All the samples show an absorption maximum in the UV region. A slight red shift is noticed in the absorption maximum of the samples calcined at $500^{\circ} \mathrm{C}$. The band gap energy of the samples were obtained from the graph plotted by taking photon energy $h v$ $(\mathrm{eV})$ on $\mathrm{X}$-axis and the modified Kubelka-Munk function $[F(R) h v]^{2}$ on Y-axis. The $\mathrm{F}(\mathrm{R})$ was calculated using the equation, $\mathrm{F}(\mathrm{R})=(1-\mathrm{R})^{2} /(2 \mathrm{R})$, where $\mathrm{R}$ is the reflectance. The plot is shown in Figure $8(\mathrm{a}-\mathrm{d})$. From the plot, it is found that the band gap energy of $\mathrm{ZnO}$ is $3.15 \pm 0.03 \mathrm{eV}$ and $3.18 \pm 0.02 \mathrm{eV}$ for $\mathrm{ZnO}(\mathrm{h})$. Similarly, the band gap energy of GN-ZnO and GN$\mathrm{ZnO}(\mathrm{h})$ was found to be $3.16 \pm 0.02 \mathrm{eV}$ and $3.20 \pm 0.02$ $\mathrm{eV}$, respectively. The red shift observed in the absorption maximum and in the energy band gap of annealed samples with respect to the parent compounds (for example, $\mathrm{GN}-\mathrm{ZnO}(\mathrm{h})$ vs. $\mathrm{GN}-\mathrm{ZnO})$ can be attributed to the increased agglomeration/change in crystallinity on annealing. ${ }^{36,37}$ In any case, all the samples have considerably lower band gap than that previously reported for bulk $\mathrm{ZnO}(3.37 \mathrm{eV}) .{ }^{38}$ The absorption edge of GN-ZnO and $\mathrm{GN}-\mathrm{ZnO}(\mathrm{h})$ shows a minute shift towards higher energy side than the edge of $\mathrm{ZnO}$ and $\mathrm{ZnO}(\mathrm{h})$, respectively. This shift can be assigned to the interaction of $\mathrm{ZnO}$ particles with graphene sheets; for example, see ref. 37.

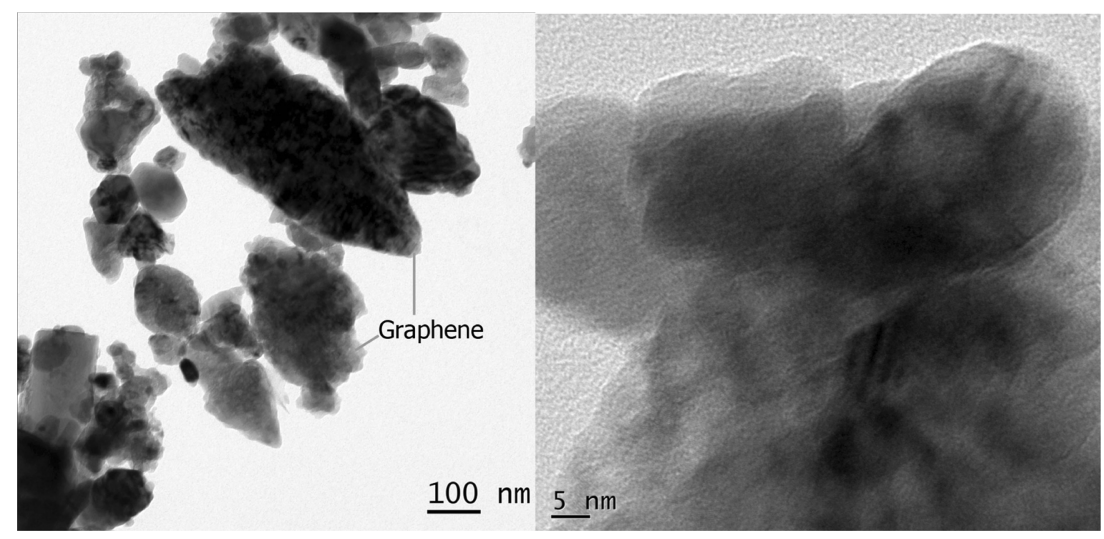

Figure 6. The HR-TEM images of GN-ZnO nanocomposite. 


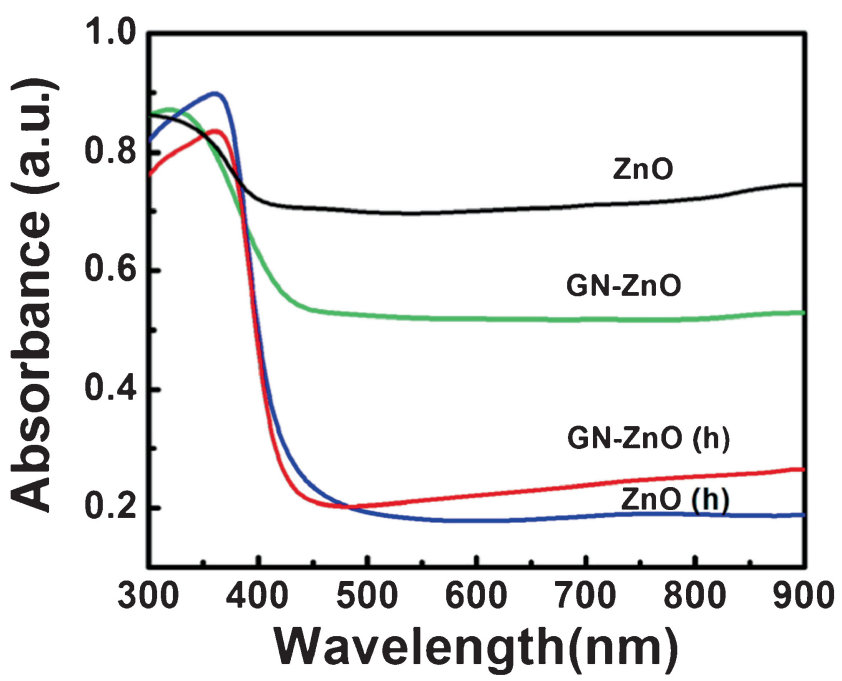

Figure 7. UV-Visible absorbance spectra of the samples: $\mathrm{ZnO}, \mathrm{GN}-\mathrm{ZnO}, \mathrm{ZnO}(\mathrm{h})$ and $\mathrm{GN}-\mathrm{ZnO}(\mathrm{h})$.

Photoluminescence (PL) experiments were conducted to study nature of defects in the composites. The $\mathrm{PL}$ of the samples $\mathrm{ZnO}(\mathrm{h})$ and $\mathrm{GN}-\mathrm{ZnO}(\mathrm{h})$ were taken to examine the defects in $\mathrm{ZnO}$ before and after the composite formation. As per reports, $\mathrm{ZnO}$ may show green, yellow, and orange PL emissions in visible region. ${ }^{40,41}$ The origin of these spectra are reportedly controversial and different defects centres are assumed to be responsible for the colours of emission. ${ }^{39}$ Based on literature, it can be concluded that green and orange-red emissions are attributed to deficiency and over-sufficiency of oxygen, respectively. The red emission is attributed to the interstitial zinc transitions. ${ }^{40-42}$ As seen in the Figure 9, PL spectra (exciting wavelength $\lambda=325 \mathrm{~nm}$ ) of both $\mathrm{ZnO}(\mathrm{h})$ and $\mathrm{GN}-\mathrm{ZnO}(\mathrm{h})$ shows a red emission at 662.5 $\mathrm{nm}$; hence it can be assigned to the over-sufficiency of oxygen and also to the interstitial zinc transition.
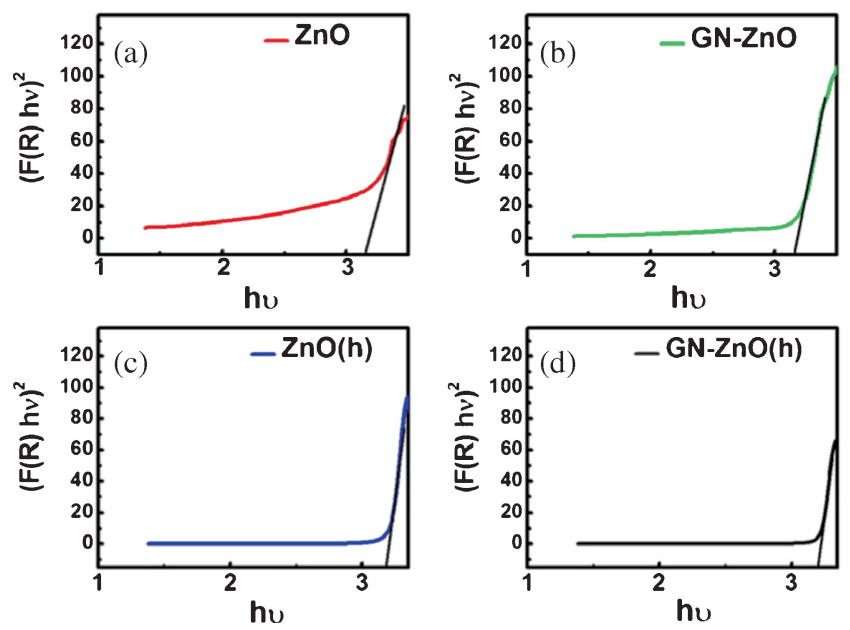

Figure 8. Plots on $(\mathrm{F}(\mathrm{R}) \mathrm{h} v)^{2} v s$. photon energy $(h v)$ of (a) $\mathrm{ZnO}$, (b) GN-ZnO, (c) $\mathrm{ZnO}(\mathrm{h})$ and (d) GN-ZnO(h).

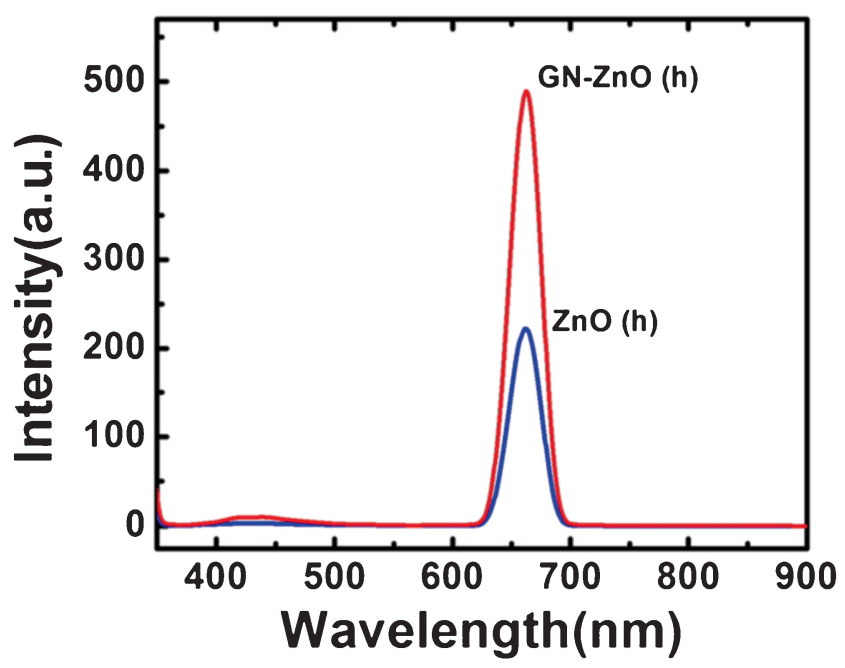

Figure 9. Room temperature PL spectra of $\mathrm{ZnO}$ and GN$\mathrm{ZnO}$, both annealed at $500^{\circ} \mathrm{C}$.

The intensity of the PL spectra peak at $662.5 \mathrm{~nm}$ was found to be nearly doubled in $\mathrm{GN}-\mathrm{ZnO}(\mathrm{h})$ compared to $\mathrm{ZnO}(\mathrm{h})$. Curiously any type of quenching due to the presence of GN is not indicated in the PL spectra. The similar behaviour of enhanced intensity is reported for $\mathrm{TiO}_{2}-\mathrm{RGO}^{43}$ The intensity increase indicates that GN$\mathrm{ZnO}(\mathrm{h})$ can reach more excited state and hence produce more photogenerated electron-hole pairs. ${ }^{43}$ So an enhanced activity can be predicted for $\mathrm{GN}-\mathrm{ZnO}(\mathrm{h})$ over $\mathrm{ZnO}(\mathrm{h})$ from $\mathrm{PL}$ spectra. It is reported that in $\mathrm{ZnO}$, with an increase in annealing temperature, the content of surface oxygen vacancy increases up to $500^{\circ} \mathrm{C} .{ }^{44}$ Beyond the annealing temperature $500^{\circ} \mathrm{C}$, the oxygen vacancy content in the surface of $\mathrm{ZnO}$ falls down. So the selection of annealing temperature as $500^{\circ} \mathrm{C}$ plays an important role in the PL peak intensity.

\subsection{Photocatalytic activity}

Photocatalytic activity of the samples was studied by employing the degradation of methylene blue (MB) solution. The photoreactor used in the experiment produces $\mathrm{UV}$ radiation at wavelength $(\lambda)$ above $270 \mathrm{~nm}$ (illuminance $150 \mathrm{~lx}$ ). From the experiment almost complete degradation of MB solution was noticed within 80-85 min for GN-ZnO. GN-ZnO(h) took only 30-35 min for the dye degradation. The variation of normalised concentration with UV irradiation time is shown in Figure 10. The degradation rate constant of the catalytic reactions can be obtained using pseudo-first order kinetic equation:

$$
\ln \left(\mathrm{C} / \mathrm{C}_{0}\right)=-\mathrm{kt}
$$

Here, $\mathrm{C}_{0}$ is the initial concentration, $\mathrm{C}$ is the concentration at time $t$, and $k$ is the degradation rate constant. 


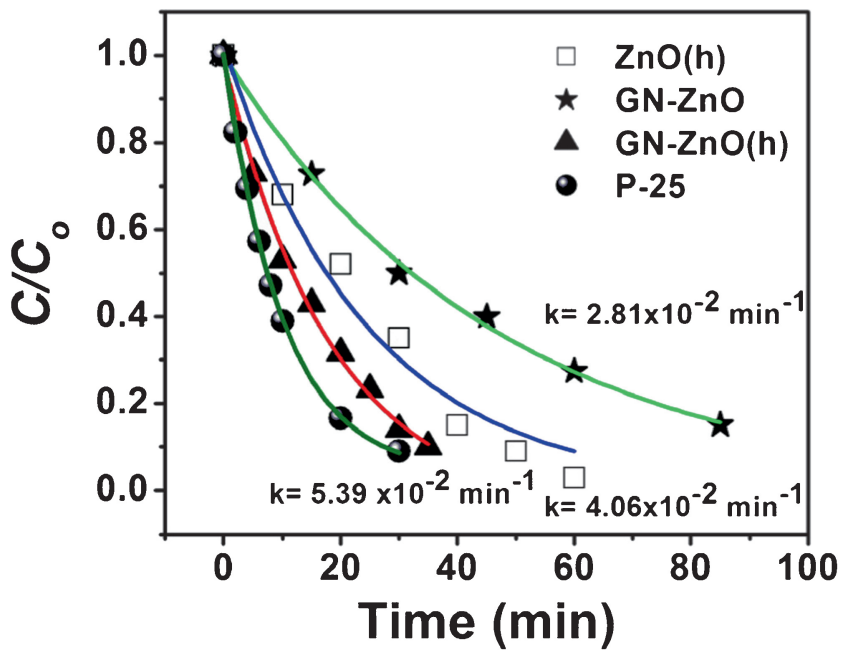

Figure 10. Comparison of photocatalytic degradation of $\mathrm{MB}$ in the presence of catalysts $\mathrm{GN}-\mathrm{ZnO}, \mathrm{ZnO}$ annealed at $500^{\circ} \mathrm{C}, \mathrm{GN}-\mathrm{ZnO}$ annealed at $500^{\circ} \mathrm{C}$ and $\mathrm{P}-25$ (see text) under UV light. The solid line shows fit to determine photocatalytic reaction rate $(k)$. The $k$ value for $\mathrm{P}-25$ is found to be $9.91 \times$ $10^{-2} \min ^{-1}$.

Table 1 summarises the photocatalytic reaction rate constants obtained from the plots (Figure 10). As expected based on the PL spectra, highest activity is shown by $\mathrm{GN}-\mathrm{ZnO}(\mathrm{h}):(5.39 \pm 0.23) \times 10^{-2} \mathrm{~min}^{-1}$. The photocatalytic activity of Degussa P-25 $\mathrm{TiO}_{2}$ (Nanoshel, 99.9\%) was also studied under the same experimental conditions as a standard photocatalyst for comparison (Figure 10). There are previous reports on the general mechanism of photocatalytic degradation of dyes. ${ }^{45} \mathrm{~A}$ schematic diagram of dye degradation mechanism for $\mathrm{GN}-\mathrm{ZnO}$ is shown in Figure 11. The UV light excites electrons from the valance band of $\mathrm{ZnO}$ to the conduction band and hence photogenerated electron - hole pairs are formed. The photogenerated electrons get transferred to the graphene sheets. The graphene acts as a trap so that it prevents quick recombination of photogenerated electron hole pairs. ${ }^{16}$ The graphenetrapped electrons will react with oxygen dissolved in water forming oxygen radicals. Furthermore, the dissolved oxygen directly reacts with excited electrons on the $\mathrm{ZnO}$ surface and creates more oxygen radicals. ${ }^{16,46}$

Table 1. Photocatalytic activity rate constant $(k)$ of catalysts.

\begin{tabular}{lc} 
Compound & $\begin{array}{c}\text { Photocatalytic activity Rate constant, } \\
k\left(10^{-2} \mathrm{~min}^{-1}\right)\end{array}$ \\
\hline $\mathrm{ZnO}(\mathrm{h})$ & $4.06( \pm 0.30)$ \\
$\mathrm{GN}-\mathrm{ZnO}$ & $2.81( \pm 0.40)$ \\
$\mathrm{GN}-\mathrm{ZnO}(\mathrm{h})$ & $5.39( \pm 0.23)$ \\
$\mathrm{P}-25 \mathrm{TiO}_{2}$ & $9.91( \pm 0.20)$ \\
\hline
\end{tabular}

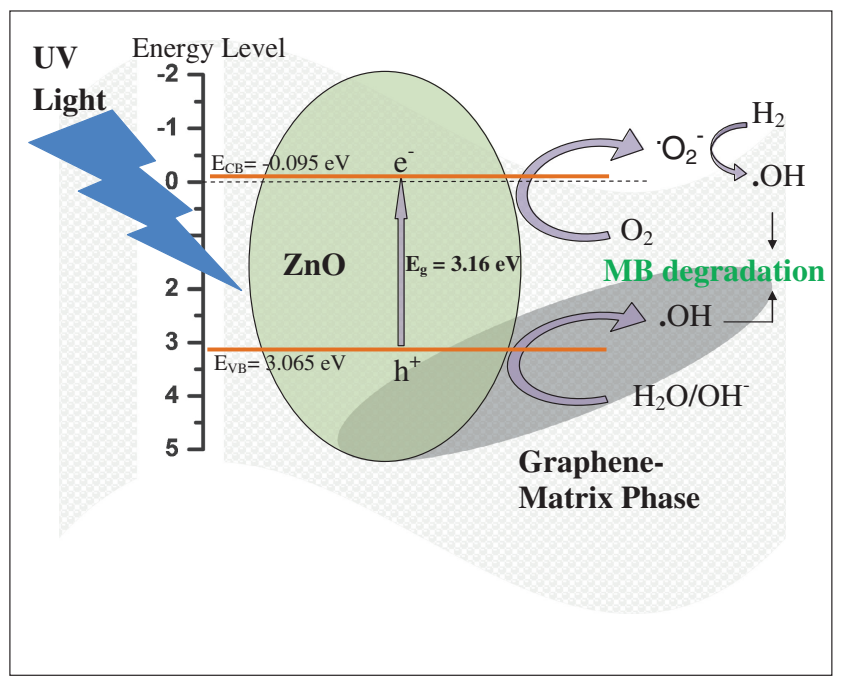

Figure 11. Schematic representation of the proposed photocatalytic degradation mechanism in MB solution under UV light irradiation in the presence of $\mathrm{GN}-\mathrm{ZnO}$ catalyst.

These oxygen radicals react with water to form reactive hydroxyl species which will degrade MB dye. In the mean time, photogenerated holes also create hydroxyl radicals, which in turn degrades the dye molecules. The reactions included in the mechanism can be summarised as follows:

$$
\begin{aligned}
& \mathrm{GN}-\mathrm{ZnO}+h v \rightarrow \mathrm{ZnO}\left(\mathrm{h}^{+}\right)-\mathrm{GN}\left(\mathrm{e}^{-}\right) \\
& \mathrm{GN}\left(\mathrm{e}^{-}\right)+\mathrm{O}_{2} \rightarrow \mathrm{GN}+\mathrm{O}_{2}^{-} \\
& \mathrm{ZnO}\left(\mathrm{h}^{+}\right)+\mathrm{H}_{2} \mathrm{O} \rightarrow \mathrm{ZnO}+\mathrm{OH}^{\cdot} \\
& \mathrm{OH}+\mathrm{MB} \rightarrow \text { Degraded products. }
\end{aligned}
$$

\section{Conclusions}

In this work, graphene and functionalised graphene with $\mathrm{ZnO}$ nanoparticles were successfully synthesised by electrochemical method. The samples are specially noted for its purity and maximum yield. Excepting the usage of $0.002 \mathrm{M}$ sulphuric acid, the graphene synthesis and graphene functionalisation can be considered as an environment friendly technique. As demonstrated for $\mathrm{ZnO}$ in this paper, the reported three step route could be adapted to other metal oxides also. On the hybridisation of $\mathrm{ZnO}$ with graphene, the band gap energy of $\mathrm{ZnO}$ got slightly shifted to higher energies. An enhanced photocatalytic activity of $\mathrm{GN}-\mathrm{ZnO}$ over $\mathrm{ZnO}$ was observed under UV light. The $\mathrm{GN}-\mathrm{ZnO}$ annealed at $500^{\circ} \mathrm{C}$ shows an efficient photocatalytic activity with a degradation rate constant of $5.39 \times 10^{-2} \mathrm{~min}^{-1}$. The methodology discussed in this report suggests a facile and efficient method for synthesis of metal oxide functionalised graphene usable for different applications such as sensing, lithium ion batteries and photocatalysis. 


\section{Supplementary Information (SI)}

Additional information (Figure S1) comparing dependence of external UV irradiation on photocatalytic activity of blank methylene blue dye without catalyst and with catalyst is available at www.ias.ac.in/chemsci.

\section{Acknowledgements}

This work is supported in part by KSCSTE Project 107/ 2016 and a grant from UGC-BSR, Govt. of India. A. R. Nanakkal acknowledges UGC-BSR SAP for fellowship assistance.

\section{References}

1. Akhavan O and Ghaderi E 2009 Photocatalytic Reduction of Graphene Oxide Nanosheets on $\mathrm{TiO}_{2}$ Thin Film for Photoinactivation of Bacteria in Solar Light Irradiation J. Phys. Chem. C 11320214

2. Geim A K and Novoselov K S 2007 The rise of graphene Nat. Mater. 6183

3. Bai S and Shen X 2012 Graphene-inorganic nanocomposites RSC Adv. 264

4. Yang Y, Ren L, Zhang C, Huang S and Liu T 2011 Facile Fabrication of Functionalized Graphene Sheets (FGS)/ZnO Nanocomposites with Photocatalytic Property ACS Appl. Mater. Interfaces 32779

5. Wang J, Tsuzuki T, Tang B, Hou X, Sun L and Wang X 2012 Reduced Graphene Oxide/ZnO Composite: Reusable Adsorbent for Pollutant Management ACS Appl. Mater. Interfaces 43084

6. Zhang Z, Xiao F, Guo Y, Wang S and Liu Y 2013 OnePot Self-Assembled Three-Dimensional $\mathrm{TiO}_{2}$ Graphene Hydrogel with Improved Adsorption Capacities and Photocatalytic and Capacities and Photocatalytic and Electrochemical Activities ACS Appl. Mater. Interfaces 52227

7. Ng Y H, Iwase A, Kudo A and Amal R 2010 Reducing Graphene Oxide on a Visible-Light $\mathrm{BiVO}_{4}$ Photocatalyst for an Enhanced Photoelectrochemical Water Splitting J. Phys. Chem. Lett. 12607

8. An X and Yu J C 2011 Graphene-based photocatalytic composites RSC Adv. 11426

9. Muthirulan P, Meenakshisundararam M and Kannan N 2013 Beneficial role of $\mathrm{ZnO}$ photocatalyst supported with porous activated carbon for the mineralization of alizarin cyanin green dye in aqueous solution $J$. $A d v$. Res. 4479

10. Fan H, Zhao X, Yang J, Shan X, Yang L, Zhang Y, Li X and Gao M 2012 ZnO-graphene composite for photocatalytic degradation of methylene blue dye Catal. Commun. 2929

11. Li B, Liu T, Wang Y and Wang Z 2012 ZnO/grapheneoxide nanocomposite with remarkably enhanced visiblelight-driven photocatalytic performance J. Colloid Interface Sci. 377114

12. Mandal S S and Bhattacharyya A J 2012 Electrochemical sensing and photocatalysis using $\mathrm{Ag}-\mathrm{TiO}_{2}$ microwires J. Chem. Sci. 124969
13. Keis K, Bauer C, Boschloo G, Hagfeldt A, Westermark K, Rensmo H and Siegbahn H 2002 Nanostructured $\mathrm{ZnO}$ electrodes for dye-sensitized solar cell applications J. Photochem. Photobiol. A 148 57-64

14. Cimitan S, Albonetti S, Forni L, Peri F and Lazzari D 2009 Solvothermal synthesis and properties control of doped ZnO nanoparticles J. Colloid Interface Sci. 329 73

15. Xu T, Zhang L, Cheng $H$ and Zhu Y 2011 Significantly enhanced photocatalytic performance of $\mathrm{ZnO}$ via graphene hybridization and the mechanism study Appl. Catal. B: Environmental 101382

16. Yin P T, Shah S, Chhowalla M and Lee K-B 2015 Design, Synthesis, and Characterization of GrapheneNanoparticle Hybrid Materials for Bioapplications Chem. Rev. 1152483

17. Alfonso Reina, Xiaoting Jia, John Ho, Daniel Nezich, Hyungbin Son, Vladimir Bulovic, Mildred S. Dresselhaus and Jing Kong 2009 Large Area, FewLayer Graphene Films on Arbitrary Substrates by Chemical Vapor Deposition Nano Lett. 9(1) 30-35

18. Hummers W S and Offeman R E 1958 Preparation of Graphitic Oxide J. Am. Chem. Soc. 801339

19. Liu N, Luo F, Wu H, Liu Y, Zhang C and Chen J 2008 One-Step Ionic-Liquid-Assisted Electrochemical Synthesis of Ionic-Liquid-Functionalized Graphene Sheets Directly from Graphite Adv. Funct. Mater. 181518

20. Guo H-L, Wang X-F, Qian Q-Y, Wang F-B and Xia X-H 2009 A Green Approach to the Synthesis of Graphene Nanosheets ACS NANO 32653

21. Wang G, Wang B, Park J, Wang Y, Sun B and Yao J 2009 Highly efficient and large-scale synthesis of graphene by electrolytic exfoliation CARBON 473242

22. Ong W-J, Voon S-Y, Tan L-L, Goh B T, Yong S-T and Chai S-P 2014 Enhanced Daylight-Induced Photocatalytic Activity of Solvent Exfoliated Graphene (SEG)/ZnO Hybrid Nanocomposites toward Degradation of Reactive Black 5 Ind. Eng. Chem. Res. 53 17333

23. Wang $\mathrm{P}$, Wang J, Ming T, Wang X, Yu H, Yu J, Wang Y and Lei M 2013 Dye-Sensitization-Induced VisibleLight Reduction of Graphene Oxide for the Enhanced TiO2 Photocatalytic Performance ACS Appl. Mater. Interfaces $\mathbf{5} 2924$

24. Kurapati R, Reddy U V, Raichur A M and Suryaprakash N 2016 Facile synthesis of Graphene Oxide/Doublestranded DNA composite Liquid crystals and Hydrogels J. Chem. Sci. 128325

25. Qiu J, Zhang $\mathrm{P}$, Ling $\mathrm{M}$, Li S, Liu $\mathrm{P}$, Zhao $\mathrm{H}$ and Zhang S 2012 Photocatalytic Synthesis of $\mathrm{TiO}_{2}$ and Reduced Graphene Oxide Nanocomposite for Lithium Ion Battery ACS Appl. Mater. Interfaces 43636

26. Chakrabarti M H, Low C T J, Brandon N P, Yufit V, Hashim M A, Irfan M F, Akhtar J, Ruiz-Trejo E and Hussain M A 2013 Progress in the electrochemical modification of graphene-based materials and their applications Electrochim. Acta $\mathbf{1 0 7} 425$

27. Low C T J, Walsh F C, Chakrabarti M H, Hashim M A and Hussain M A 2013 Electrochemical approaches to the production of graphene flakes and their potential applications CARBON 541 
28. Reddy T N, Manna J and Rana R K 2015 PolyamineMediated Interfacial Assembly of rGO-ZnO Nanostructures: A Bio-inspired Approach and Enhanced Photocatalytic Properties ACS Appl. Mater. Interfaces 7 19684

29. Yang M-Q and Xu Y-J 2013 Basic Principles for Observing the Photosensitizer Role of Graphene in the Graphene-Semiconductor Composite Photocatalyst from a Case Study on Graphene-ZnO J. Phys. Chem. C 11721724

30. Malevu T D and Ocaya R O 2015 Effect of Annealing Temperature on Structural, Morphology and Optical properties of $\mathrm{ZnO}$ Nano-Needles prepared by Zinc Air Cell System Method Int. J. Electrochem. Sci. 10 1752

31. Terrones M, Botello-Méndez A R, Campos-Delgado J, López-Urías F, Vega-Cantú Y I, Rodríguez-Macíasd F J, Elías A L, Muñoz-Sandoval E, Cano-Márquez A G, Charlier J-C and Terrones H 2010 Graphene and graphite nanoribbons: Morphology, properties, synthesis, defects and applications Nano Today 5351

32. Shen L, Zhang X, Li H, Yuan C and Cao G 2011 Design and Tailoring of a Three-Dimensional $\mathrm{TiO}_{2}-$ Graphene-Carbon Nanotube Nanocomposite for Fast Lithium Storage J. Phys. Chem. Lett. 23096

33. Wang X, Wang J, Wang D, Dou S, Ma Z, Wu J, Tao L, Shen A, Ouyang C, Liu Q and Wang S 2014 Onepot synthesis of nitrogen and sulfur co-doped graphene as efficient metal-free electrocatalysts for the oxygen reduction reaction Chem. Commun. 504839

34. Umair A and Raza H 2012 Controlled synthesis of bilayer graphene on nickel Nanoscale Res. Lett. 7 437

35. Low J, Yu J and Ho W 2015 Graphene-Based Photocatalysts for $\mathrm{CO}_{2}$ Reduction to Solar Fuel J. Phys. Chem. Lett. 64244

36. Kumar S S, Venkateswarlu P, Rao V R and Rao G N 2013 Synthesis, characterization and optical properties of zinc oxide nanoparticles Int. Nano Lett. 330
37. Baruwati B, Kumar D K and Manorama S V 2006 Hydrothermal Synthesis of Highly Crystalline $\mathrm{ZnO}$ Nanoparticles: A Competitive Sensor for LPG and EtOH Sens. Actuators B 119676

38. Janotti A and de Walle C G Van 2009 Fundamentals of zinc oxide as a semiconductor Rep. Prog. Phys. 72 126501

39. Stengl V, Popelkov D and Vlacil P $2011 \mathrm{TiO}_{2}$-Graphene Nanocomposite as High Performance Photocatalysts $J$. Phys. Chem. C 11525209

40. Tam K H, Cheung C K, Leung Y H, Djurišić A B, Ling C C, Beling C D, Fung S, Kwok W M, Chan W K, Phillips D L, Ding L and Ge W K 2006 Defects in ZnO Nanorods Prepared by a Hydrothermal Method J. Phys. Chem. B 11020865

41. Özgür O U, Alivov Ya I, Liu C, Teke A, Reshchikov M A, Doğan S, Avrutin Cho S-J and Morkoç H 2005 A comprehensive review of $\mathrm{ZnO}$ materials and devices $J$. Appl. Phys 98041301

42. Willander M, Nur O, Sadaf J R, Qadir M I, Zaman S, Zainelabdin A, Bano N and Hussain I 2010 Luminescence from Zinc Oxide Nanostructures and Polymers and their Hybrid Devices Materials 32643

43. Gu Y, Xing M and Zhang J 2014 Synthesis and photocatalytic activity of graphene based doped $\mathrm{TiO} 2$ nanocomposites Appl. Surf. Sci. 3198

44. Liu D, Lv Y, Zhang M, Liu Y, Zhu Y, Zong R and Zhu Y 2014 Defect-related photoluminescence and photocatalytic properties of porous $\mathrm{ZnO}$ nanosheets J. Mater. Chem. A 215377

45. Shah Md. S A S, Park A R, Zhang K, Park J H and Yoo P J 2012 Green Synthesis of Biphasic $\mathrm{TiO}_{2}-$ Reduced Graphene Oxide Nanocomposites with Highly Enhanced Photocatalytic Activity ACS Appl. Mater. Interfaces 43893

46. Xia W, Wang H, Zeng X, Han J, Zhu J, Zhou M and Wu S 2014 High-efficiency photocatalytic activity of type II $\mathrm{SnO} / \mathrm{Sn}_{3} \mathrm{O}_{4}$ heterostructures via interfacial charge transfer CrystEngComm 166841 